\title{
A Case of Proliferative Myositis Arising from the Sternocleidomastoid Muscles: Diagnosis and Treatment
}

\author{
Bo Hae Kim ${ }^{1}$ (D), Wook Jang ${ }^{1}$, Sang Woo Kim ${ }^{1}$, and Woo-jin Jeong ${ }^{2}$ \\ ${ }^{1}$ Department of Otorhinolaryngology-Head and Neck Surgery, Dongguk University Ilsan Hospital, Dongguk University College of \\ Medicine, Goyang; and ${ }^{2}$ Department of Otorhinolaryngology-Head and Neck Surgery, Seoul National University Bundang Hospital, \\ Seoul National University College of Medicine, Seongnam, Korea
}

\author{
흥쇄유돌근에서 기인한 증식근육염 1예: 진단과 치료 \\ 김보해 ${ }^{1} \cdot$ 장 욱 $^{1} \cdot$ 김상우 $^{1} \cdot$ 정우진 $^{2}$ \\ 동국대학교 의과대학 일산병원 이비인후-두경부외과학교실, ${ }^{1}$ 서울대학교 의과대학 분당서울대학교병원 이비인후-두경부외과학교실 ${ }^{2}$
}

\author{
Received January 3, 2020 \\ Revised February 13, 2020 \\ Accepted February 28, 2020 \\ Address for correspondence \\ Bo Hae Kim, MD, PhD \\ Department of Otorhinolaryngology- \\ Head and Neck Surgery, \\ Dongguk University Ilsan Hospital, \\ Dongguk University \\ College of Medicine, \\ 27 Dongguk-ro, Ilsandong-gu, \\ Goyang 10326, Korea \\ Tel $+82-31-961-7438$ \\ Fax +82-31-961-7427 \\ E-mail bohae111@naver.com
}

We describe here diagnosis treatment of a case that rose from the sternocleidomastoid muscle and was treated without surgical excision. A 56-year-old man presented with a rapidly growing, painless and not well-circumscribed mass at the right side of the neck. We diagnosed this tumor as proliferative myositis (PM) based on the typical findings from ultrasonography, computed tomography, and core-needle biopsy, and treated it without surgical excision. Herein we report a successful diagnosis and treatment process of a case of PM, which was followed-up with ultrasonography.

Korean J Otorhinolaryngol-Head Neck Surg 2020;63(11):537-40

Key Words Core needle biopsy · Proliferative myositis · Treatment · Ultrasonography.

\section{Introduction}

Proliferative myositis (PM) is a rare inflammatory disease, commonly presenting as a rapidly growing lesion accompanied by diffuse infiltration of the muscular tissue. ${ }^{1)} \mathrm{PM}$, benign lesion, a usually develops in the upper extremities and, because of its rapid growth, mimics malignant tumors like sarcomas. ${ }^{1)}$ Although PM in the head and neck region is a relatively rare disease with approximately 100 cases reported in the literature, it should be considered an important differential diagnosis, relative to sarcoma and other head and neck diseases, to avoid unnecessary surgical procedures for its di-

This is an Open Access article distributed under the terms of the Creative Commons Attribution Non-Commercial License (https://creativecommons.org/licenses/by-nc/4.0) which permits unrestricted non-commercial use, distribution, and reproduction in any medium, provided the original work is properly cited. agnosis and treatment. ${ }^{2,3)}$ We report a case of PM arising from the sternocleidomastoid muscle (SCM), including details of the preoperative radiologic evaluation, histopathology on the core-needle biopsy (CNB), and the clinical course with follow-up by ultrasonography.

\section{Case}

A 56-year-old healthy man presented to the outpatient clinic with a three day history of a rapidly growing and painless mass on the right side of the neck, without general symptoms such as fever or weight loss. Physical examination revealed an approximately $4 \mathrm{~cm}$ mass in the mid-portion of the SCM, on the right side. There were no other palpable or visible lesions in the oral cavity or neck and endoscopic examination 
also showed no abnormal findings in the upper-aero-digestive tract.

On suspicion of a metastatic lymph node (LN) or sarcoma, computed tomography (CT) was performed. A heterogeneous and poorly demarcated intramuscular mass, approximately 4 by $4 \mathrm{~cm}$, was identified by $\mathrm{CT}$ on the right side of the neck. There were no additional abnormal findings, such as LN enlargement or destruction of the surrounding tissues (Fig. 1A). The CT was followed by ultrasonography, which revealed hyper-echoic fibers, approximately $3 \mathrm{~mm}$ in diameter, running parallel to the SCM muscle in a "steel cable-like" pattern (Fig. 1B). Following a consultation with a radiologist, with PM under consideration, a CNB was performed. The CNB specimen, stained by hematoxylin and eosin, showed infiltrated muscle fibers, forced aside by strands of proliferative fibroblasts and fibrous tissues, in a "checkerboard" pattern (Fig. 2A). There were also ganglion-like giant cells with abundant basophilic cytoplasms and vesicular nuclei with prominent nucleoli (Fig. 2B). Although mitotic figures were focally identified, consistent with the rapid growth of PM, there were no signs of atypical cells or mitosis. In subsequent immunochemical staining, the tumor was positive for smooth muscle actin and partially positive for Ki-67. Staining was negative for the sarcoma markers desmin and myogenin.

We prescribed $80 \mathrm{mg}$ of zaltoprofen three times a day to the patient for two weeks after the histologic confirmation of PM. After the administration of zaltoprofen for two weeks, the size of the lesion decreased dramatically from 4 to $2 \mathrm{~cm}$. By six weeks, it had disappeared, as indicated by both physical examination and ultrasonography (Fig. 3).

\section{Discussion}

Here, we report a case of PM originating from SCM that we
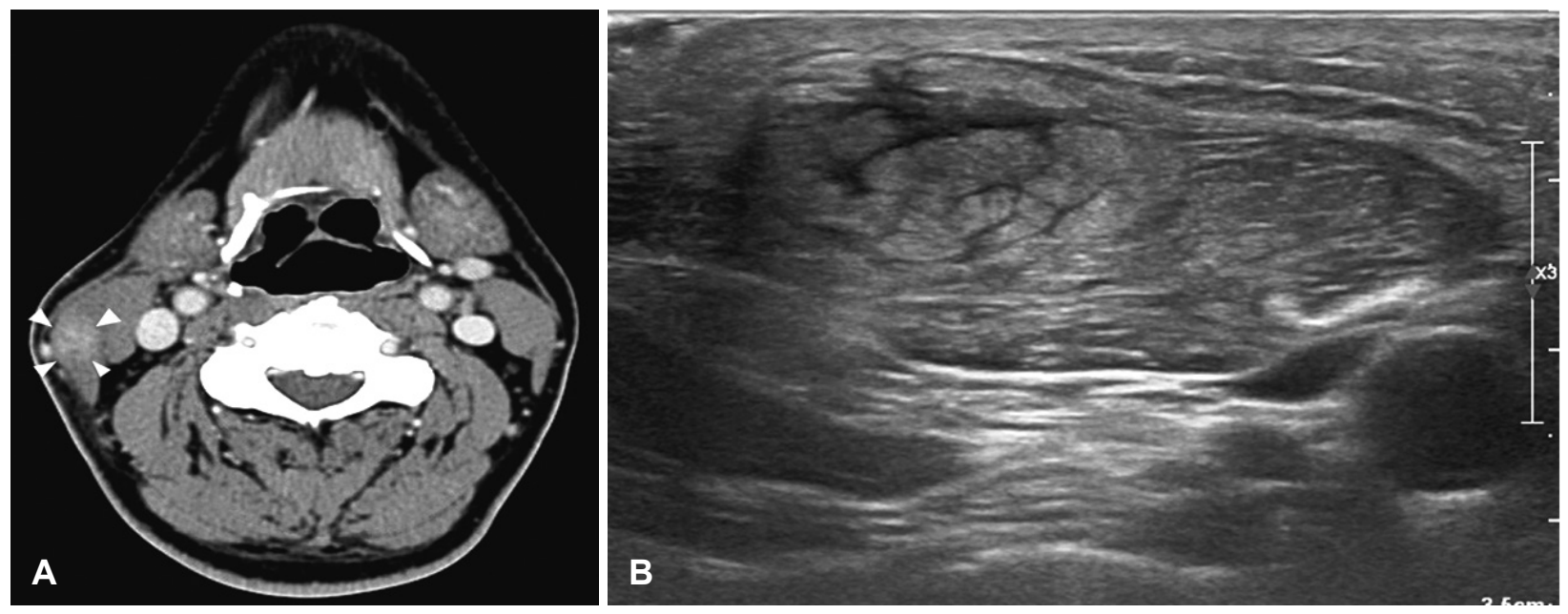

Fig. 1. Axial CT image of the neck (contrast) showing heterogeneous enhancement and poorly demarcated lesion within the right SCM (A). "Steel cable-like" pattern of the right SCM was identified on ultrasonography (B). SCM: sternocleidomastoid muscle.
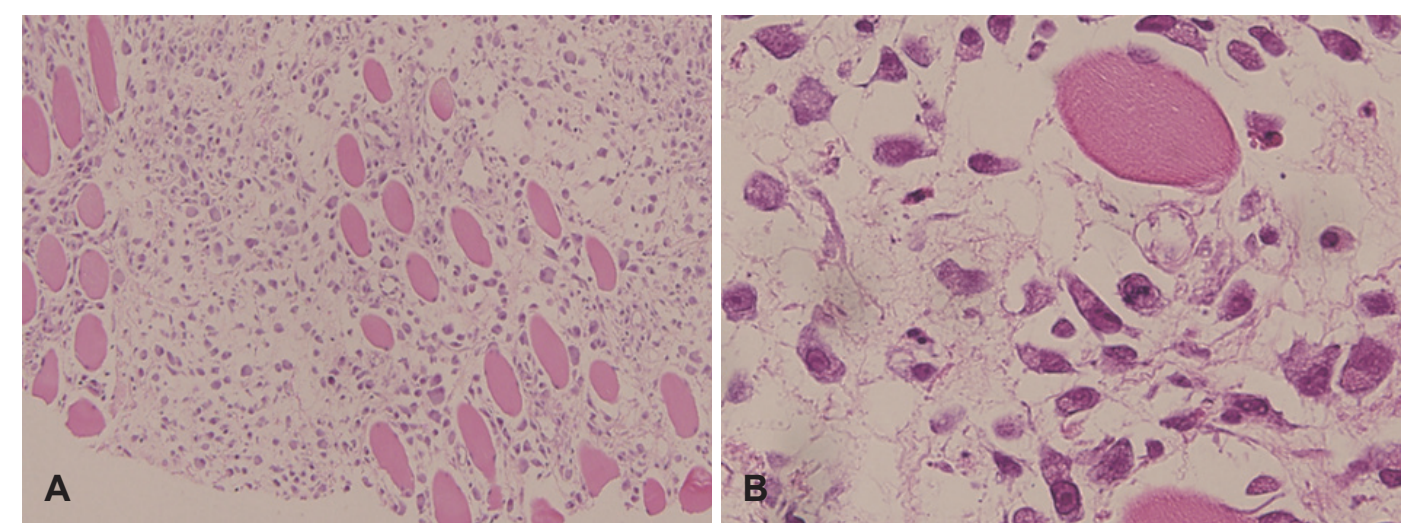

Fig. 2. Hematoxylin and eosin-stained sections. Muscle fibers were infiltrated and forced aside by strands of proliferative fibroblasts and fibrous tissue $(\times 100)(A)$. Ganglion-like giant cells had abundant basophilic cytoplasm and vesicular nuclei with prominent nucleoli $(\times 400)(B)$. 


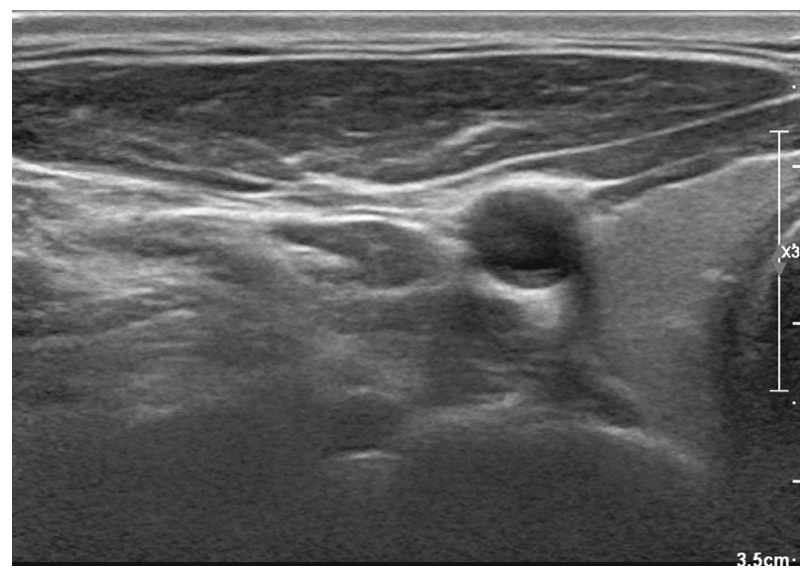

Fig. 3. Ultrasonographic image showed that previous lesion in the muscle was normalized at six weeks after the initial presentation.

diagnosed using minimally invasive tests, including imaging and $\mathrm{CNB}$, in a healthy man who, subsequently, received conservative management. We confirmed the complete resolution of the PM by ultrasonography.

Although the etiology of PM is still not well known, several theories have been proposed as possible causes, including focal trauma, local ischemia, paracrine myopathy and chromosomal translocation. ${ }^{1,3)}$ PM, first reported by Kern ${ }^{1)}$ in 1960, is a benign, spontaneously resolving lesion. Therefore, if it is appropriately diagnosed, surgical excision can be avoided. PM is a rare pathologic condition, primarily developing in the upper extremities as a rapidly growing tumor-like lesion, with characteristics that can mimic sarcoma. Therefore diagnosing PM of the head and neck at its initial presentation is difficult.

PM usually presents as a rapidly growing mass, without signs of inflammation or LN enlargement, as it did in our case. Radiologic evaluations, especially ultrasonography, are very important for diagnosing PM. In our patient, CT was initially performed under the suspicion of a metastatic LN or sarcoma, but the CT images showed a poorly demarcated intramuscular mass within the SCM muscle and no evidence of malignancy. Furthermore, ultrasonography showed a "steel cable-like" pattern, a pathognomonic pattern found in PM, presenting hypo-echoic geometric lines within dense and hyper-echoic muscle. ${ }^{3-5)}$ Although this pathognomonic pattern of PM was identified on ultrasonography, CNB was also performed for a definitive diagnosis. ${ }^{3)}$ Although fine needle aspiration is a useful tool for the differential diagnosis between PM and malignant soft tissue lesion, CNB can also provide not only a differential diagnosis between PM and malignant soft tissue lesion but also additional information about the tumor grade. Since we suspected this lesion to be a sarcoma, we used CNB, considering its advantage. ${ }^{6,7)}$ The result, a "checkerboard" pattern with myofibroblasts infiltrating the surrounding muscles and ganglion-like basophilic giant cells, are specific histopathologic findings associated with PM. Although many studies reported histopathologic findings in samples obtained by surgical excision, the minimally invasive collection of specimens is important to consider for PM, avoiding surgical incision or excision. CNB procedures may provide a large enough specimen to diagnose PM.

Because PM is a self-limiting lesion and malignant transformation or recurrence of PM has never been reported, its best-recommended treatment is watchful waiting. ${ }^{8,9)}$ If, however, the lesion causes movement impairment or cosmetic problems, surgical excision can be considered. In our case, the patient was prescribed zaltoprofen for two weeks because we believed that inflammatory reactions were involved in the rapid growth of the PM. The palpable lesion was dramatically decreased after zaltoprofen administration. At six weeks after the initial presentation, there was no evidence of PM, by either physical examination or ultrasonography.

In conclusion, since PM is a rare and benign lesion that spontaneously resolves within several weeks, accurate diagnosis is important to avoid unnecessary surgical excision. It can be diagnosed using ultrasonography to detect the pathognomonic characteristic, a "steel cable-like" pattern, along with $\mathrm{CNB}$, a minimally invasive technique for obtaining specimens for histopathology. Thus, PM can be managed conservatively, without surgical excision.

\section{Acknowledgments}

The authors thank Hyun Jung Lim, MD for helping us writing a draft of this manuscript.

\section{Author Contribution}

Conceptualization: Bo Hae Kim. Data curation: Bo Hae Kim, Woo-jin Jeong. Formal analysis: Bo Hae Kim. Methodology: Bo Hae Kim. Supervision: Bo Hae Kim. Visualization: Bo Hae Kim, Sang Woo Kim. Writing - original draft: Bo Hae Kim, Woo-jin Jeong. Writing — review \& editing: Wook Jang, Bo Hae Kim.

\section{ORCID}

Bo Hae Kim

https://orcid.org/0000-0002-4645-0678

\section{REFERENCES}

1) Kern WH. Proliferative myositis; a pseudosarcomatous reaction to injury: A report of seven cases. Arch Pathol 1960;69:209-16.

2) Enzinger FM, Dulcey F. Proliferative myositis. Report of thirtythree cases. Cancer 1967;20(12):2213-23.

3) Fauser C, Nährig J, Niedermeyer HP, Arnold W. Proliferative myositis: A rare pseudomalignant tumor of the head and neck. Arch Otolaryngol Head Neck Surg 2008;134(4):437-40. 
4) Sarteschi M, Ciatti S, Sabò C, Massei P, Paoli R. Proliferative myositis: Rare pseudotumorous lesion. J Ultrasound Med 1997; 16(11):771-3.

5) Pagonidis K, Raissaki M, Gourtsoyiannis N. Proliferative myositis: Value of imaging. J Comput Assist Tomogr 2005;29(1):108-11.

6) Klapsinou E, Despoina P, Dimitra D. Cytologic findings and potential pitfalls in proliferative myositis and myositis ossificans diagnosed by fine needle aspiration cytology: Report of four cases and review of the literature. Diagn Cytopathol 2012;40(3):239-44.
7) Heslin MJ, Lewis JJ, Woodruff JM, Brennan MF. Core needle biopsy for diagnosis of extremity soft tissue sarcoma. Ann Surg Oncol 1997;4(5):425-31.

8) Lundgren L, Kindblom LG, Willems J, Falkmer U, Angervall L. Proliferative myositis and fasciitis. A light and electron microscopic, cytologic, DNA-cytometric and immunohistochemical study. APMIS 1992;100(5):437-48.

9) Mulier S, Stas M, Delabie J, Lateur L, Gysen M, Dal Cin P, et al. Proliferative myositis in a child. Skeletal Radiol 1999;28(12):703-9. 